\title{
Hypoglossal nerve stimulation for treatment of obstructive sleep apnea (OSA): a primer for oral and maxillofacial surgeons
}

\author{
Sung ok Hong ${ }^{1}$, Yu-Feng Chen ${ }^{2,3}$, Junho Jung ${ }^{4}$, Yong-Dae Kwon ${ }^{2,5^{*}}$ (D) and Stanley Yung Chuan Liu ${ }^{6 *}$
}

\begin{abstract}
The prevalence of obstructive sleep apnea (OSA) is estimated to be 1-5\% of the adult population world-wide, and in Korea, it is reported at $4.5 \%$ of men and 3.2\% of women (Age 40 to 69 years old). Active treatment of OSA is associated with decrease in insulin resistance, cardiovascular disease, psychosocial problems, and mortality. Surgical treatment of OSA has evolved in the era of neuromodulation with the advent of hypoglossal nerve stimulation (HGNS). We share this review of HGNS with our maxillofacial surgical colleagues to expand the scope of surgical care for OSA.
\end{abstract}

Keywords: Hypoglossal nerve, Upper airway stimulation, Obstructive sleep apnea, Snoring, Sleep endoscopy, OSA surgical treatment, Oral and maxillofacial surgeon

\section{Introduction}

\section{OSA prevalence}

The prevalence of obstructive sleep apnea (OSA) is estimated to be $2-5 \%$ of the adult population [1]. In Korea, OSA is reported in $4.5 \%$ of men and $3.2 \%$ of women between the ages of 40 to 69 years [2]. Despite a lower prevalence of obesity as compared to Western countries, the prevalence is similar in Korea. Active treatment of OSA decreases the incidence of insulin resistance, cardiovascular disease, psychosocial problems, and mortality [3-6].

\section{OSA treatment}

Non-surgical treatments for OSA include weight loss, behavioral modifications, mandibular advancement device (MAD), and continuous positive airway pressure (CPAP). CPAP is considered as first-line treatment for OSA with well documented efficacy and morbidity. As a treatment modality, its adherence rate ranges from 39 to $50 \%$ [7-9]. Surgical options include soft tissue and skeletal reconstruction of the upper airway. Soft tissue procedures include septoplasty, various forms of uvulopalatopharyngoplasty, tongue base reduction, and hyoid

\footnotetext{
*Correspondence: kwony@khu.ac.kr; yongdae.kwon@gmail.com; ycliu@stanford.edu

${ }^{2}$ Stanford University School of Medicine, Stanford, CA, USA

${ }^{6}$ Department of Otolaryngology, Stanford University School of Medicine,

Stanford, CA, USA

Full list of author information is available at the end of the article
}

suspension. Common skeletal procedures include genioglossus advancement, maxillary expansion, and maxillomandibular advancement (MMA). Except for tracheostomy and MMA, anatomically modifying surgeries of the upper airway report success rates ranging from $20 \%$ to $60 \%$ [10]. Besides tracheostomy, MMA is the most effective surgical treatment with success rates as high as $85.5 \%$ [11] Neurostimulation for stability of the upper airway during sleep was introduced as an option that may be less invasive and more effective in the well-selected patient [12].

\section{Review}

Upper airway stimulation (hypoglossal nerve stimulation) History and evolution of the HGNS concept

Animal studies have confirmed that the genioglossus muscle is a key protrusion muscle, as opposed to the styloglossus and hyoglossus muscles which retract the tongue [13]. In 1989, Miki et al. found a relationship between the hypoglossal nerve and upper airway resistance during stimulation in six canines [14]. In 1992, Schwarz et al. reported a correlation of V1max stimulation and decrease in critical closing pressure (Pcrit) in 18 decerebrate felines. Yoo et al. suggested that multi-contact nerve electrodes can be effective in achieving upper airway dilation and patency by selective activation of various branches of the hypoglossal nerve in eight beagles [15]. Oliven et al. reported on the effect of airway modulation by selectively 
stimulating protrusor and retrusor muscles in anesthetized canines [16]. The study confirmed that selective genioglossus muscle stimulation significantly stabilized the airway while stimulation of the styloglossus and hyoglossus muscles collapsed the airway.

The first attempt to improve upper airway patency in humans via neurostimulation was performed by Guilleminault et al. [17]. Transcutaneous submental and intraoral electrical stimulation of the upper airway muscles was attempted with limited success. Preliminary successful human studies were first reported in 1996 by Schwartz et al. [18]. By intramuscular stimulation of the lingual muscle in nine participants, the frequency of airway collapse decreased without causing sleep arousal. A pilot study in 2001 proposed that unilateral electrical stimulation of the hypoglossal nerve was a feasible and potential therapeutic option for OSA [19]. Efficacy of OSA treatment was shown in seven of the eight hypoglossal nerve stimulation (HGNS) implanted patients (Inspire Medical systems, Maple Grove, MN). For the 6-month continuation of the study, the results were consistent; they were not successful in the long term due to technical defects that led to device dysfunction [20].

\section{HGNS devices and device concepts}

Following the published technical limitations of the human pilot study in 2001, several investigators and medical device companies focused on improvements over a decade. In 2011, three clinical trials were sponsored by different and independent firms: Apnex (St. Paul, MN, USA), Inspire (Maple Grove, MN, USA), and ImThera Medical (San Diego, CA, USA).

Apnex and Inspire are based on unilateral inspiratory stimulation to the medial branch of the hypoglossal nerve. The two devices differed in inspiration sensors; Apnex was a double impedance sensor positioned over the lower ribs of both hemithoraces while Inspire was an effort sensor placed between the intercostal muscles.

Eastwood et al. [21] were the first to report results from the Apnex trial. This clinical trial was performed in Australia enrolling 37 patients and ultimately implanting 21. Inclusion criteria consisted of patients with AHI between 20 and 100 events per hour (at least 80\% hypopnea), BMI $<40(\mathrm{~kg} / \mathrm{m} 2)$, and age between 21 and 70 years. The 6-month follow-up yielded successful results with more than $50 \%$ reduction in the AHI. But the larger scale phase 2-3 clinical trial did not deliver anticipated results with mean AHI decrease from 45 to 25 [22]. Surgically unsuccessful results led to cessation of device development.

Van de Heyning et al. [23] subsequently published the results from the 6-month clinical trial with the Inspire II device. It was a two-part study with the first consisting of a wide inclusion and exclusion criteria. The 20 patients enrolled in the study had BMI $<35(\mathrm{~kg} / \mathrm{m} 2)$ and AHI $>25$ events per hour. Fourteen patients showed the predicted outcome, and six patients showed greater than $50 \%$ reduced AHI that was also less than 20 events per hour after 6 months. The second part narrowed the criteria based on the findings from part one and included drug-induced sleep endoscopy (DISE) as a diagnostic modality. The inclusion criteria were BMI less than 32 $(\mathrm{kg} / \mathrm{m} 2)$, AHI between 20 and 50 events per hour, and absence of complete concentric collapse (CCC) of the velum as seen during DISE. Seven of the eight implanted patients assessed at 6 months post operatively showed successful results.

Succeeding the Inspire II trial, a larger multicenter 1-year phase 2-3 trial (STAR trial) was completed in 2014 by Strollo et al. [12]. One hundred twenty-six patients were enrolled with inclusion criteria consisting of CPAP nonadherence, BMI less than $32(\mathrm{~kg} / \mathrm{m} 2)$, AHI between 20 to 50 events per hour, absence of significant positional or central apneas, and absence of CCC on DISE at the velum. Sixty-six percent of the patients had achieved surgical success. The device was then FDA approved.

Mwenge et al. [24] performed a 1-year clinical study treating 14 OSA patients with the ImThera Medical device. Stimulation was delivered at both inspiration and expiration and thereby excluding the need of an inspiratory sensor. The hypoglossal nerve electrode was cuffed on the main trunk and targeted all muscles in the hemilateral tongue. Inclusion criteria consisted of BMI between 25 and $40(\mathrm{~kg} / \mathrm{m} 2)$, AHI below 20 events per hour, Mallampati score $1-3$, and palatine tonsils grade $0-2$. Ten of the 13 implanted patients achieved surgical success with mean AHI decrease from 45.2 to 21 events per hour. Currently, a larger phase $2-3$ trial is underway.

\section{Surgical technique}

The HGNS system (Inspire, Maple Grove, MN, USA) is comprised of three parts: stimulation cuff electrode, pleural pressure sensing lead, and implantable pulse generator (IPG).

Simulation cuff electrode The stimulation cuff electrode is wrapped around the medial branches of the right hypoglossal nerve and protrudes and stiffens the tongue to mitigate airway collapse. First, a 5-cm horizontal incision is made 1 fingerbreadth below the right mandible border with the submandibular gland as the posterior boundary extending anteriorly towards the midline. The digastric tendon is identified and retracted inferiorly while the submandibular gland is lifted postero-superiorly. The posterior edge of the mylohyoid muscle is retracted anteriorly to visualize the space where the main trunk of the hypoglossal nerve is usually 
positioned and branches. The vena comitans overlying the nerve can be ligated for better access of the hypoglossal nerve branches. The functional break point is located between the medial and lateral branches of the main hypoglossal nerve trunk. Using a nerve integrity monitoring system (NIM, Medtronic Xomed, Jacksonville, Fl), [10] the medial branches of the hypoglossal nerve are confirmed and the cuff selectively wraps around these branches (Fig. 1).

Pleural pressure sensing lead The pleural pressure sensing lead detects ventilator effect and sends this information to the IPG which in turn activates the hypoglossal nerve stimulation cuff. The respiratory effort-sensing lead coordinates stimulation during the most vulnerable part of the respiratory cycle (end expiratory phase). Stimulation is given between end-expiration through the inspiratory period to minimize neuromuscular fatigue [25]. A horizontal incision is made at the right fourth or fifth intercostal space lateral to the nipple line. Dissection is carried out to the upper border of the underlying rib, and a pocket is tunneled postero-anteriorly between the external and internal intercostal muscle layers where the sensing lead faces the pleura (Fig. 2).

Implantable pulse generator The IPG connects both the hypoglossal nerve stimulation cuff and pleural sensing electrode. It receives the information from the pleural sensing electrode and generates a pulse that is transferred to the stimulation cuff. The IPG pocket is created 2 to $5 \mathrm{~cm}$ inferior to the right clavicle and medial to the delto-pectoral groove. The pocket is deep to the subcutaneous fat and superficial to the pectoralis major muscle fascia. Inferiorly, the pocket is extended by tunneling subcutaneously to the pleural sensing electrode. Superiorly, the pocket is extended from the clavicle to the hypoglossal nerve stimulation cuff by tunneling at the subplatysmal level.

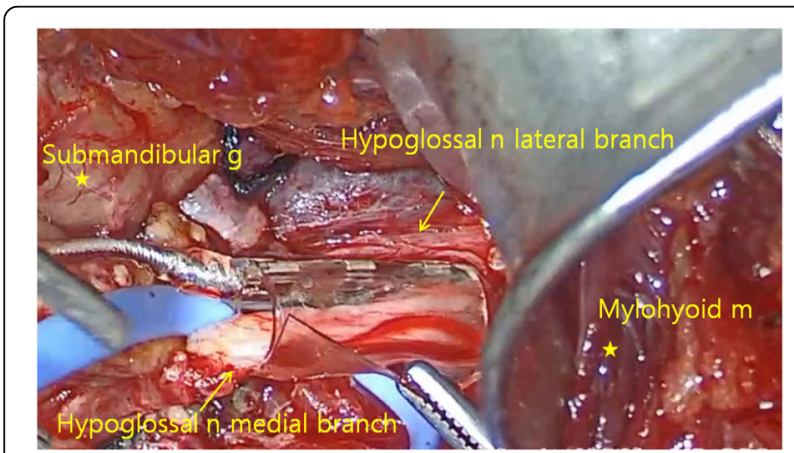

Fig. 1 Cuff electrodes encircling the medial branch of hypoglossal nerve with three stimulation nodes. Note the lateral branch is not included in the cuff. ( $n$ nerve, $m$ muscle, $g$ gland)

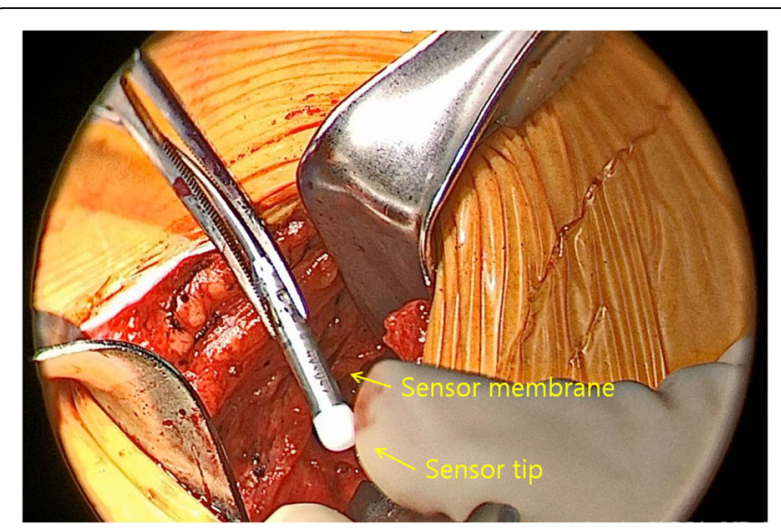

Fig. 2 Pleural pressure sensing lead is placed with the ventilatory sensor facing the pleura

After HGNS systems are implanted, the IPG is tested to confirm tongue protrusion prior to closure (Fig. 3).

\section{Advantages of HGNS}

Even though CPAP is a treatment for OSA that has welldocumented efficacy and low morbidity, the adherence rate is low [7]. In patients with CPAP intolerance, HGNS can be an effective alternative. Daily use of the device at 12 months was $86 \%$ and daily use at 18 months was $84 \%$ [26]. The advantage of HGNS being a titratable therapy like CPAP or MAD is especially beneficial as OSA is a chronic condition that needs monitoring and reevaluation due to aging, weight gain, and decrease in elasticity of the soft tissues.

Another advantage of HGNS is that as a one-time procedure it improves airway collapsibility at multiple levels. DISE and fluoroscopy studies have shown retrolingual and retropalatal space enlargement with HGNS [27, 28]. HGNS directly opens the hypopharyngeal airway with tongue protrusion, but it also impacts the retropalatal

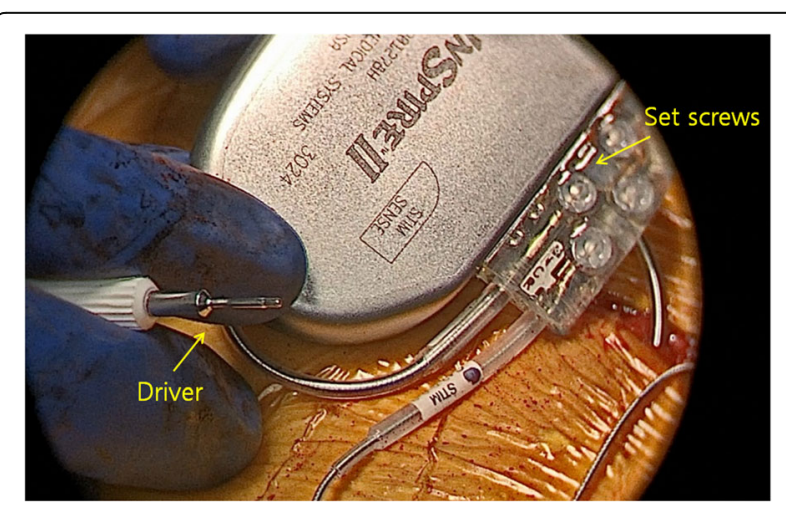

Fig. 3 Implantable pulse generator (IPG) has two $3.2 \mathrm{~mm}$ low profile connector ports (STIM port, SENSE port) which house the stimulation and pleural pressure sensing lead connectors. The lead connectors are secured with set screws using a driver 
airway. Its mechanism restores muscle tone to avoid upper airway collapse during sleep.

\section{Complications of HGNS}

Strollo et al. announced the overall rate of serious adverse effects to be less than 2\% [12] with no serious IPG device infection requiring explantation and no permanent hypoglossal nerve damage. There is also less postoperative discomfort as compared to other soft tissue and skeletal operations [25]. Discomfort in the IPG position, tongue stiffness, tongue abrasion, transient ipsilateral tongue paresis, and post-operative swelling were the reported side effects. Most were minor and can be mitigated by meticulous surgical techniques, adjustment of stimulation parameters, dental adjustments, and the use of mouth guards.

\section{Limitations of HGNS}

Woodson et al. reported the 36-month postoperative outcome data of the STAR trial patients [29]. Continued follow-up supporting the use of HGNS is warranted. Another limitation is the narrow selection criteria. Patients over BMI $32 \mathrm{~kg} / \mathrm{m} 2$ are excluded from HGNS as success rates become inconsistent. Nevertheless, the prevalence of obesity is high and continues to increase [30]. The high cost of the HGNS implant is another limitation to wide application. Another drawback of HGNS is the current size of the IPG and MRI incompatibility.

\section{Conclusions}

\section{Role of oral and maxillofacial surgeons}

Beyond soft tissue and skeletal reconstruction of the upper airway, oral and maxillofacial surgeons should be familiar with neuromodulation of the upper airway and its latest outcomes and technique updates. With unpredictability of surgical results from soft tissue surgery and the reluctance of many patients to undergo major facial skeletal changes, HGNS is a viable option that is needed in the scope of sleep apnea surgical care. Evaluation of dynamic airway collapse patterns using DISE is an important prerequisite.

\section{Conclusion}

Currently, only one device is FDA approved for HGNS. The inclusion criteria are failure of CPAP adherence, BMI less than $32 \mathrm{~kg} / \mathrm{m} 2$, AHI between 20 to 50 events per hour, absence of CCC seen on DISE at the velum, and absence of significant positional or central apneas. Stanford's sleep surgery team with maxillofacial surgeons Riley and Liu has reported the first post-MMA relapse followed by successful treatment of OSA via HGNS [31]. Familiarity with HGNS as an alternative to upper airway reconstruction augments the maxillofacial surgeon's comprehensive care for patients with OSA.
Funding

None.

Ethics approval and consent to participate Not applicable.

\section{Authors' contributions}

SOH wrote the manuscript. YDK and SYC conceived the study and participated in its design and helped to draft the manuscript. FYC and $J J$ edited the manuscript. All authors read and approved the final manuscript.

\section{Competing interests}

The authors declare that they have no competing interests.

\section{Publisher's Note}

Springer Nature remains neutral with regard to jurisdictional claims in published maps and institutional affiliations.

\section{Author details}

${ }^{1}$ Department of Dentistry (Oral and Maxillofacial Surgery), Catholic Kwandong University School of Medicine, International St. Mary's Hospital, Incheon, South Korea. ${ }^{2}$ Stanford University School of Medicine, Stanford, CA, USA. ${ }^{3}$ Department of Oral and Maxillofacial Surgery, Kaohsiung Medical University Hospital, Kaohsiung, Taiwan. ${ }^{4}$ Department of Oral and Maxillofacial Surgery, Kyung Hee University Dental Hospital, Seoul, Republic of Korea. ${ }^{5}$ Department of Oral and Maxillofacial Surgery, Center for Refractory Jawbone Diseases, School of Dentistry, Kyung Hee University, Seoul, Republic of Korea. ${ }^{6}$ Department of Otolaryngology, Stanford University School of Medicine, Stanford, CA, USA

Received: 25 May 2017 Accepted: 1 August 2017

Published online: 25 September 2017

References

1. Friedman M (2009) Sleep apnea and snoring, ed. E Inc China 452. p. 3

2. Kim J, In K, Kim J, You S, Kang K, Shim J et al (2004) Prevalence of sleepdisordered breathing in middle-aged Korean men and women. Am J Respir Crit Care Med 170(10):1108-1113

3. Punjabi NM, Shahar E, Redline S, Gottlieb DJ, Givelber R, Resnick HE et al (2004) Sleep-disordered breathing, glucose intolerance, and insulin resistance: the Sleep Heart Health Study. Am J Epidemiol 160(6):521-530

4. Punjabi NM, Caffo BS, Goodwin JL, Gottlieb DJ, Newman AB, O'Connor GT et al (2009) Sleep-disordered breathing and mortality: a prospective cohort study. PLoS Med 6(8):e1000132

5. Rodenstein D (2009) Sleep apnea: traffic and occupational accidents_-individual risks, socioeconomic and legal implications. Respiration 78(3):241-248

6. Gottlieb DJ, Yenokyan G, Newman AB, O'Connor GT, Punjabi NM, Quan SF et al (2010) Prospective study of obstructive sleep apnea and incident coronary heart disease and heart failure: the sleep heart health study. Circulation 122(4):352-360

7. Kushida CA, Nichols DA, Holmes TH, Quan SF, Walsh JK, Gottlieb DJ et al (2012) Effects of continuous positive airway pressure on neurocognitive function in obstructive sleep apnea patients: The Apnea Positive Pressure Long-term Efficacy Study (APPLES). Sleep 35(12):1593-1602

8. Rosen CL, Auckley D, Benca R, Foldvary-Schaefer N, Iber C, Kapur V et al (2012) A multisite randomized trial of portable sleep studies and positive airway pressure autotitration versus laboratory-based polysomnography for the diagnosis and treatment of obstructive sleep apnea: the HomePAP study. Sleep 35(6):757-767

9. Richard W, Venker J, den Herder C, Kox D, van den Berg B, Laman M et al (2007) Acceptance and long-term compliance of nCPAP in obstructive sleep apnea. Eur Arch Otorhinolaryngol 264(9):1081-1086

10. Heiser C, Hofauer B, Lozier L, Woodson BT, Stark T (2016) Nerve monitoringguided selective hypoglossal nerve stimulation in obstructive sleep apnea patients. Laryngoscope 126(12):2852-2858

11. Zaghi S, Holty JE, Certal V, Abdullatif J, Guilleminault C, Powell NB et al (2016) Maxillomandibular advancement for treatment of obstructive sleep apnea: a meta-analysis. JAMA Otolaryngol Head Neck Surg 142(1):58-66

12. Strollo PJ Jr, Soose RJ, Maurer JT, de Vries N, Cornelius J, Froymovich O et al (2014) Upper-airway stimulation for obstructive sleep apnea. N Engl J Med 370(2):139-149 
13. Fairbanks DW, Fairbanks DN (1993) Neurostimulation for obstructive sleep apnea: investigations. Ear Nose Throat J 72(1):52-54 57

14. Miki H, Hida W, Shindoh C, Kikuchi Y, Chonan T, Taguchi O et al (1989) Effects of electrical stimulation of the genioglossus on upper airway resistance in anesthetized dogs. Am Rev Respir Dis 140(5):1279-1284

15. Yoo PB, Durand DM (2005) Effects of selective hypoglossal nerve stimulation on canine upper airway mechanics. J Appl Physiol 99(3):937-943

16. Oliven A, Odeh M, Schnall RP (1996) Improved upper airway patency elicited by electrical stimulation of the hypoglossus nerves. Respiration 63(4):213-216

17. Guilleminault C, Hill MW, Simmons FB, Dement WC (1978) Obstructive sleep apnea: electromyographic and fiberoptic studies. Exp Neurol 62(1):48-67

18. Schwartz AR, Eisele DW, Hari A, Testerman R, Erickson D, Smith PL (1996) Electrical stimulation of the lingual musculature in obstructive sleep apnea. J Appl Physiol 81(2):643-652

19. Schwartz AR, Bennett ML, Smith PL, De Backer W. Hedner J, Boudewyns A et al (2001) Therapeutic electrical stimulation of the hypoglossal nerve in obstructive sleep apnea. Arch Otolanyngol Head Neck Surg 127(10):1216-1223

20. Kezirian EJ, Boudewyns A, Eisele DW, Schwartz AR, Smith PL, Van de Heyning PH et al (2010) Electrical stimulation of the hypoglossal nerve in the treatment of obstructive sleep apnea. Sleep Med Rev 14(5):299-305

21. Eastwood PR, Barnes M, Walsh JH, Maddison KJ, Hee G, Schwartz AR et al (2011) Treating obstructive sleep apnea with hypoglossal nerve stimulation. Sleep 34(11):1479-1486

22. Kezirian EJ, Goding GS Jr, Malhotra A, O'Donoghue FJ, Zammit G, Wheatley JR et al (2014) Hypoglossal nerve stimulation improves obstructive sleep apnea: 12-month outcomes. J Sleep Res 23(1):77-83

23. Van de Heyning PH, Badr MS, Baskin JZ, Cramer Bornemann MA, De Backer WA, Dotan $Y$ et al (2012) Implanted upper airway stimulation device for obstructive sleep apnea. Laryngoscope 122(7):1626-1633

24. Mwenge GB, Rombaux P, Dury M, Lengele B, Rodenstein D (2013) Targeted hypoglossal neurostimulation for obstructive sleep apnoea: a 1-year pilot study. Eur Respir J 41(2):360-367

25. Dedhia RC, Strollo PJ, Soose RJ (2015) Upper aimay stimulation for obstructive sleep apnea: past, present, and future. Sleep 38(6):899-906

26. Strollo PJ Jr, Gillespie MB, Soose RJ, Maurer JT, de Vries N, Cornelius J et al (2015) Upper airway stimulation for obstructive sleep apnea: durability of the treatment effect at 18 months. Sleep 38(10):1593-1598

27. Safiruddin F, Vanderveken OM, de Vries N, Maurer JT, Lee K, Ni Q et al (2015) Effect of upper-airway stimulation for obstructive sleep apnoea on airway dimensions. Eur Respir J 45(1):129-138

28. Goding GS Jr, Tesfayesus W, Kezirian EJ (2012) Hypoglossal nerve stimulation and airway changes under fluoroscopy. Otolaryngol Head Neck Surg 146(6):1017-1022

29. Woodson BT, Soose RJ, Gillespie MB, Strohl KP, Maurer JT, de Vries N et al (2016) Three-year outcomes of cranial nerve stimulation for obstructive sleep apnea: the STAR trial. Otolaryngol Head Neck Surg 154(1):181-188

30. WHO. Obesity and overweight June 2016 [cited 2016 June]; Available from: http://www.who.int/mediacentre/factsheets/fs311/en/

31. Liu SY, Riley RW (2017) Continuing the original Stanford sleep surgery protocol from upper airway reconstruction to upper airway stimulation: our first successful case. J Oral Maxillofac Surg 75(7):1514-1518

\section{Submit your manuscript to a SpringerOpen ${ }^{\circ}$ journal and benefit from:}

- Convenient online submission

- Rigorous peer review

- Open access: articles freely available online

- High visibility within the field

- Retaining the copyright to your article

Submit your next manuscript at $\gg$ springeropen.com 